\title{
Recentralização/Descentralização dinâmica do regime federativo no Brasil dos anos 90
}

\author{
EDUARDO KUGELMAS
}

LOURDESSOLA

RESUMO: Este artigo discute a evolução das práticas e instituições federativas no Brasil dos anos recentes, enfatizando a simultaneidade de processos de recentralização e descentralização. A trajetória descentralizadora que culmina com a Constituição de 1988, a crise fiscal do estado brasileiro e os efeitos do Plano Real são discutidos a partir de um quadro de referências de tipo comparativo, que busca incorporar escritos muito recentes de Alfred Stepan.

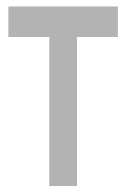

omemos como ponto de partida uma metáfora amplamente utilizada nas análises em torno do regime federativo no caso brasileiro, a da sístole/diástole, ou seja, a da alternância de períodos de centralização e de descentralização na história do país, identificando-se habitualmente a centralização com o autoritarismo e a descentralização com avanços democráticos. Assim, à monarquia de formato unitário seguiu-se a "Primeira República" (1889-1930), quando se institucionalizou o regime federativo no país, sendo a Constituição de 1891 seu primeiro marco institucional. A Revolução de 1930 e a ascensão de Vargas abrem um período centralizador que culmina com o Estado Novo (1937-1945). O período democrático da Constituição de 1946 é interrompido pelo regime militar de 1964 que se estende até 1985. Neste momento, a centralização autoritária atinge seu ponto máximo, na década de 70, com os governos Medicie Geisel. A transição democrática tem como momento emblemático a Constituição de 1988, considerada um marco de descentralização federativa.

Este relato tantas vezes repetido é, porém, problemático. A tão sedutora metáfora, atribuída ao general Golbery do Couto e Silva e que tem sua

UNITERIMOS:

federalismo, políticas públicas.

Professor do Departamento de Ciência Política da FFLCH - USP

Professora do Departamento de Ciência Política da FFLCH - USP 
origem no pensamento de Vilfredo Pareto é excessivamente simplista e pode conduzir a equívocos.

Ficam na sombra alguns aspectos de continuidade nestes processos que são essenciais para a melhor compreensão da evolução do regime federativo e da oscilação entre centralização e descentralização. Se há um movimento pendular, não há simetria neste movimento. Nem o Estado Novo chega a destruir a estrutura federativa, nem a Constituição de 1946 abala o reforço do governo central e sua ampliação de atribuições (cf. Campello de Souza, 1976). Mais perto do momento atual, o regime autoritário controlou ferreamente os níveis subnacionais de poder, principalmente através das eleições indiretas para os governos estaduais e da centralização fiscal. Por outro lado não excluiu as elites políticas regionais do pacto de dominação e manteve em boa medida as atribuições administrativas das esferas subnacionais (cf. Souza, 1997). A célebre metáfora pode induzir a crença de uma anulação completa dos mecanismos institucionais anteriores a cada movimento pendular, quando o que de fato ocorre é uma modificação do padrão de relacionamento entre as esferas, através de uma dinâmica de aperto/afrouxamento de controles políticos e fiscais ${ }^{1}$.

Ressaltar estes aspectos é de peculiar relevância para uma análise da rica e complexa conjuntura recente, onde convergem aspectos recentralizadores e descentralizadores. Vem daí a importância de buscarmos superar a útil mas insuficiente idéia da alternância de momentos de centralização e de descentralização, buscando os contextos políticos e institucionais da atuação dos principais atores envolvidos e permanecendo atentos as manifestações de path dependence.

Para a análise da evolução recente do regime federativo no país primeiramente discutiremos alguns aspectos conceituais e a seguir procederemos a uma avaliação das transformações ocorridas no padrão de relacionamento entre os componentes da federação a partir da Constituição de 1988, com ênfase na questão fiscal.

\section{Conceitos, comparações, contextos}

As definições de federalismo giram, reiteradamente, em torno de um problema nada trivial da teoria política, a questão da soberania. Nas polities de tipo federativo, por mais distintas que sejam as fórmulas adotadas, sempre se coloca a coexistência de duas instâncias governativas. Seja qual for a definição adotada, - e é difícil superar em concisão a clássica fórmula de Danniel Elazar, um dos maiores estudiosos do tema, que resume a essência do federalismo em self-rule plus shared rule - sempre se coloca a questão de uma soberania dual ou de uma soberania compartilhada (cf. Elazar, 1987).

Por longo tempo preponderaram as abordagens de tipo jurídico-for-

Críticas ao uso abusivo da metáfora, baseadas em outras linhas de argumentação podem ser vistas em Fiori (1995) e Sallum Jr. (1996). mal, quase exclusivamente circunscritas ao campo do direito constitucional. $\mathrm{O}$ exemplo arquetípico desta abordagem é o livro de Kenneth Wheare, Federal Government, de 1946, muitas vezes reeditado e atualizado (cf. Wheare, 1970). Na tentativa de superar este enfoque considerado demasiado estreito surgiu uma ampla literatura que examina o tema do ângulo da ciência política e também um 
extenso conjunto de estudos sobre a temática do federalismo fiscal, visto como capítulo da área das finanças públicas ${ }^{2}$. Examinaremos a seguir algumas contribuições recentes ao debate do ângulo da ciência política que nos permitam colocar melhor a discussão dos processos ora em curso no Brasil.

Stepan (1997) busca estabelecer alguns pontos de partida para uma análise comparativa dos sistemas federais existentes. Nesta tarefa, seu procedimento é o de realizar uma avaliação crítica dos trabalhos de William Riker, talvez o mais influente dos autores que estudaram o federalismo do ângulo da ciência política (cf. Riker, 1964). Para Stepan, a abordagem de Riker privilegia demasiadamente as federações constituídas através do arquétipo americano, o da convenção constitucional de Filadélfia, em 1787. Deste ângulo seriam federações apenas os resultados de pactos entre entidades previamente soberanas. O ponto central dos estudos sobre o federalismo seria, desta forma, a negociação inicial, o bargaining entre as partes para dar origem e posteriormente manter e viabilizar o estado federado. A distinta trajetória histórica dos estados unitários que se transformaram em federações nãoé, pois, levada devidamente em conta. Como lembra Stepan, além das coming together federations, do modelo americano, um quadro de referência analítico deve, necessariamente, incluir as holding together federations, sendo exemplos recentes as constituições da Espanha, de 1976 e da Bélgica, de 1993. Para nosso país, isto traz ecos de discussões antigas, que remontam à própria fundação da Republica Federativa ${ }^{3}$. Outro ponto levantado é o do caráter paradoxal de uma afirmação de Riker, para quem a existência ou não de instituições federativas seria de pouca importância na definição e adoção de políticas, ou seja, teriam escassa relevância na definição de outcomes, o que é vigorosamente contestado por Stepan.

O esforço maior deste é o de trazer elementos que permitam comparar os sistemas federativos existentes, avaliando o grau e a intensidade das conexões entre seus traços definidores e a consolidação e/ou aperfeiçoamento das instituições democráticas. Criticando não somente a Riker mas o conjunto da literatura por darem insuficiente atenção às relações entre federalismo e democracia, Stepan vai chegar à seguinte definição:

É provável que os sistemas democráticos não possam ser chamados de sistemas federais, a não ser que preencham dois critérios. Primeiramente, no interior do Estado nacional devem existir subunidades políticas territoriais cujo eleitorado seja exclusivamente composto por cidadãos da subunidade e que possuam áreas de autonomia e soberania jurídicas e de elaboração de políticas constitucionalmente garantidas. Em segundo lugar, deve existir uma unidade política nacional que contenha um Legislativo eleito pelo conjunto da população e que tenha algumas áreas jurídicas e políticas de competência garantidas constitucionalmente com pertencentes à soberania da entidade nacional (Stepan, 1997, p. 15).
2 Para uma excelente avaliação das limitações de uma abordagem ao tema apoiada exclusivamente no enfoque de finanças públicas, cf. Aguirre \& Moraes (1997).

3 Entre outros, Ruy Barbosa enfatizou esta característica do surgimento do federalismo entre nós. Torres (1961) discute amplamente o tema. 
Em outras palavras, uma federação democrática é aquela em que os cidadãos participam pelo voto em duas diferentes instâncias, com atribuições diversas e com definições constitucionais nítidas sobre a natureza destas mesmas atribuições. Em termos ideais, estes cidadãos teriam identidades políticas duplas porém complementares.

Eexatamente a partir das enormes dificuldades em alcançar tal equilíbrio que Stepan vai procurar avaliar a estrutura e o funcionamento das federações existentes. Primeiramente, ressalta a importância substantiva do tema, ao lembrar que embora as federações sejam poucas (aproximadamente dez por cento do total de países membros das Nações Unidas) incluem alguns dos maiores países do mundo tanto em extensão territorial como em população - os Estados Unidos, a Rússia, a Índia e o Brasil, também um dos maiores em área, o Canadá, e a principal potência econômica do continente europeu, a Alemanha. A seguir, Stepan discute o caráter necessariamente consociativo das organizações federativas, no sentido da existência inevitável de mecanismos que limitam as maiorias. Todas as federações têm dispositivos que protegem minorias e/ou fazem distinções de tipo territorial no estabelecimento das regras de representação, o que as aproxima do modelo consociativo no sentido atribuído ao termo por Lipjhart (1984).

Em consequiência, há uma maior complexidade no próprio funcionamento do sistema e faz parte das regras do jogo constitucional uma limitação aos critérios mais simples de acatamento às maiorias. A existência de uma Câmara no Congresso que represente as entidades subnacionais - estados, províncias, regiões, cantões, Lander - é uma das principais destas regras; outra é a dificuldade maior nos processos de modificação constitucional e na exclusão formalizada de determinados temas das agendas político-institucional, sendo a própria organização federativa um destes temas. Stepan sugere, como recurso analítico, a comparação entre as federações em termos da maior ou menor incidência de mecanismos do tipo majority-constraining e chega à conclusão de que o Brasil é um dos casos onde tais mecanismos são mais fortes.

Outra análise importante é a de Gagnon (1997), que enfatiza no federalismo seu caráter instrumental na solução de conflitos. Em suas palavras:

O sucesso dos sistemas federais não deve ser medido em termos da eliminação de conflitos sociais, mas sim pela capacidade de regular e gerenciar tais conflitos. $E$ completamente equivocado esperar que ofederalismo resolva os conflitos sociais. Na realidade, pode apenas amenizar tensões e ser sensivel à diversidade. Os conflitos devem ser vistos com componentes inerentes à todas as sociedades federais (Gagnon 1997, p. 18).

Em seu balanço dos estudos sobre o tema, Gagnon também acentua um aspecto metodológico, defendendo a perspectiva de uma difícil mas necessária combinação da análise institucional e da perspectiva estrutural, que procura apreender as raízes (socioeconômicas, culturais, lingüísticas territoriais) da tensão entre homogeneidade e heterogeneidade, entre unidade e diversidade, tensão esta que caracteriza todos os arranjos federativos. 
Desta discussão sobre enfoques analíticos podem ser retiradas algumas conclusões especialmente relevantes para o caso brasileiro. Como pano de fundo, podem ser ressaltadas a importância de uma visão comparativa e a necessidade de cautela frente a um normativismo ingênuo, que valorize de forma invariavelmente positiva as experiências federativas. Outro ponto fundamental é a compreensão da natureza essencialmente política dos processos federativos como mecanismos e arranjos de solução de conflitos, o que é muito distinto de umenfoque formalizante em que se aprova (ou desaprova) uma organização federativa concreta de acordo com a maior ou menor distância a um modelo idealizado.

Em outras palavras, a perspectiva analítica mais promissoraé a de examinar o tipo de heterogeneidade existente e as possibilidades dos distintos arranjos federativos em processar as diversidades de forma a manter (ou não) a unidade do Estado nacional. Chamam especialmente a atenção, pela sua dramaticidade, os conflitos que por vezes eclodem nos países que adotaram o regime federativo para acomodar diversidades étnicas, lingüísticas e religiosas. A tragédia iugoslava pode ser vista como um caso em que os mecanismos federativos foram manifestadamente insuficientes para conter a extensão e profundidade das clivagens. No caso da Índia, é freqüente que se ponha em dúvida a estabilidade das instituições democráticas. Continua presente no cenário canadense a incerteza sobre a situação futura do Quebec. Mesmo na federação arquetípica, os Estados Unidos, o arranjo inicial foi posto duramente à prova na Guerra da Secessão.

Em países como o Brasil, os conflitos a serem processados são de outra natureza. O que está aqui em causa é o quadro de clivagens regionais notoriamente marcado por notáveis desigualdades, a fragmentação do sistema político, as dificuldades da representação e a questão da indefinição - não apenas institucional ou administrativa - do escopo e alcance da atividade estatal e da divisão de competências entre os três níveis de poder. Mais do que um tema específico, a questão da federação no Brasil confunde-se com a própria formação histórica do Estado nacional $^{4}$ e permeia o conjunto de questões da agenda do país.

\section{União e Estados - desequilíbrios e reequilíbrios}

No momento da promulgação da Constituição de 1988 a reação à centralização fiscal do regime autoritário atingiu seu ponto culminante; o padrão de organização federativa que então emerge é tido como um dos mais descentralizados entre os países em desenvolvimento. São conhecidas as características da centralização anterior, estabelecida pela reforma tributária de 1966 e pela Constituição de 1967. Neste período, ampliou-se a capacidade extrativa da União, reforçou-se a dependência dos Estados menos desenvolvidos, receptores da maior parcela das transferências do Fundo de Participação dos Estados e limitou-se a autonomia administrativa dos governos estaduais, ao atribuir ao Senado a fixação das alíquotas do ICM, sua grande fonte de receita própria. Tais medidas eram perfeitamente congruentes com outras medidas concentradoras de poder, como o estabelecimento de controles sobre o aparato policial dos Estados. Do lado político, o mecanismo de eleições indiretas pelas obedientes As-
4 As contribuições de Aspasia Camargo e José Murilo Carvalho ao volume organizado por Marcello Carmagnani (1993) aprofundam esta discussão. 
sembléias Legislativas estaduais equivalia a uma indicação do poder central.

Com o desencadeamento do processo de abertura no governo Geisel (1974-1979) surgem algumas modificações no quadro. Torna-se mais importante para o regime a participação das elites regionais agrupadas no partido oficialista, a ARENA e uma emenda constitucional vai elevar os percentuais destinados aos Fundos de Participação. Por outro lado, são tomadas medidas destinadas a aumentar ainda mais a sobre-representação parlamentar dos Estados menores e menos desenvolvidos, com o objetivo expresso de contrabalançar o crescimento político e eleitoral do MDB (então único partido de oposição) nas regiões Sul e Sudeste.

Como tem sido apontado nos estudos sobre a transição política, a realização das eleições diretas para os governos estaduais em 1982 foi o ponto de inflexão decisivo. Vitoriosos nos três principais Estados do país, São Paulo, Minas Gerais e Rio de Janeiro, os governadores então eleitos vão impulsionar a campanha pelas eleições diretas para a Presidência, que, embora frustrada abre o caminho para a eleição indireta da chapa Tancredo Neves José Sarney, assinalando o fim do período autoritário 5 .

Do ponto de vista deste trabalho é fundamental enfatizar a sequiência dos eventos. É excepcional, talvez único nas transições democráticas a realização de eleições de nível subnacional antes de um pacto nacional ou de eleições gerais. O contraste entre a situação brasileira e o caso da Espanha, onde foi trilhado o caminho inverso foi apontado em estudos comparativos, como o de Stepan \& Linz (1996).

Com a eleição de 1982, criou-se no país uma situação já por vezes descrita como de diarquia ${ }^{6}$, a de coexistência de duas fontes de legitimação; o conjunto de governadores e não apenas os eleitos pela oposição passa a atuar com desenvoltura, demonstrando que a capacidade política e administrativa dos governos estaduais tinha sobrevivido, em estado latente, durante a etapa anterior. Do lado fiscal, a nova constelação de forças logo se refletiu no início de um processo de desconcentração de recursos. Graças à aprovação da emenda Passos Porto em 1983, foram elevados os percentuais dos Fundos de Participação, e também modificados os critérios de cálculo de forma favorável aos entes subnacionais. Entre 1983 e 1988, inverte-se a tendência das duas décadas anteriores e a participação da União no total da receita disponível decresce, passando de 69,8 \% a 60,1 \%.

Durante o período da "Nova República", cresce a margem de manobra e o poder de influência dos governadores. Vai-se constituindo o que Abrucio (1998) denominou "federalismo estadualista", caracterizado pelo amplo raio de manobra dos governadores no quadro de seus estados e pela forte influência que exercem sobre as respectivas bancadas no Congresso nacional. Dada a notória debilidade do sistema partidário e o relativo enfraquecimento da Presidência no

5 Para uma revisão da década de 80 , cf. Sallum Jr. (1996).

6 Para uma discussão a respeito desta dupla legitimidade, cf. Lamounier (1985). período Sarney, os governadores tornam-se atores políticos de especial relevância, o que terá imediatas consequiências fiscais. Conseguem a federalização da dívida externa, o que significa a transformação desta em dívida de longo prazo para com o Tesouro Nacional e resistem as várias tentativas de repactuação de seu estoque de dívidas feitas pelo governo federal, que busca, sem sucesso, divi- 
dir com os estados os ônus do ajuste externo.

A Constituição de 1988, votada pelo Congresso eleito em 1986 e portanto numa eleição "casada", simultânea à eleição dos governadores, refletirá com nitidez esta correlação de forças. Ao longo de todo o período de abertura, fortalecera-se no país a noção de associação ou até simbiose entre descentralização e democratização.

Foi neste ambiente que se deu início, no primeiro trimestre de 1987, ao processo de elaboração da nova Constituição. A reação natural a 20 anos de concentração do poder político alçou o fortalecimento da Federação à condição de seu principal objetivo no que toca ao Estado brasileiro. Tal objetivo exigia, no que diz respeito às finanças públicas, o aumento do grau de autonomia fiscal dos estados e municípios, a desconcentração dos recursos tributários disponíveis e a transferência de encargos da União para aquelas unidades (Versano et alii, 1998, p. 12).

Durante os debates da Assembléia, foi-se gerando uma coalizão (explícita ou implícita) entre os Estados mais desenvolvidos do Sudeste e do Sul, interessados em aumentar sua capacidade em gerar receitas próprias e os menos desenvolvidos, desejosos em fazer crescer sua parcela de participação nas receitas transferidas. Embora conflitassem em torno a outros temas, como o da política de desconcentração industrial, todos coincidiam na busca de mais recursos fiscais.

Como seria de se esperar, emergiu um modelo de Federação notavelmente descentralizado, com uma peculiaridade que o singulariza de forma marcante no contexto internacional, que é a menção explícita do município como ente federado no próprio texto constitucional (Art. 18). Estabeleceu-se uma progressiva ampliação dos percentuais da arrecadação do imposto de renda e do IPI destinados aos fundos de participação, atingindo em 1993 a 21,5\% e 22,5\%, respectivamente. Outras formas de repartição dos recursos arrecadados a nível federal foram também especificadas no Art. 159. O principal recurso estadual, o ICM teve suas bases ampliadas e transformou-se no atual ICMS. Também os municípios foram beneficiados pelo aumento do percentual a eles destinado deste último imposto.

Em consequiência, a participação federal na receita disponível passa de $61,1 \%$ em 1989 para 56,4 \% em 1996. A dos estados cresce de $25 \%$ a $27 \%$ enquanto a parcela dos municípios sobe de $13,9 \%$ a $16,7 \%$ no mesmo período (Versano et alii, 1998). Segundo estimativas do Banco Mundial, a despesa estadual cresceu 33\% entre 1986 e 1995, em termos reais, enquanto o crescimento do PIB foi de apenas 14\% (cf. Dillinger \& Webb, 1999, p. 23).

Uma das respostas do governo federal foi o aumento das contribuições sociais -COFINS, PIS-PASEP e outras, fontes de receita que não precisam ser partilhadas com as instâncias subnacionais. Segundo a opinião unânime dos peritos em questões tributárias, isto significou um aumento da irracionalidade do sistema fiscal. (cf. Versano et alii, 1998).

Descrevendo o processo brasileiro, dois conhecidos especialistas 
assim resumem o modelo que emerge:

"A lógica para aumentar recursos e poderes nas mãos dos governos intermediários e/ou locais é, antes de tudo, enfraquecer o governo central... A descentralização não nasce de uma ação da política fiscal ou econômica, mas sim de uma reação dos governos subnacionais, ou em favor destes, contra os poderes ditos excessivos do centro" (Afonso \& Lobo, 1996, p. 10)

O que seria o reverso da moeda, ou seja, a transferência de encargos não ocorre de forma sistemática, permanecendo até hoje um objetivo a atingir. Uma das características do modelo federativo brasileiro é o grande número de competências conjuntas dos três níveis, sem uma definição clara das respectivas esferas. Como será visto mais adiante, este é um dos problemas mais ponderáveis no equacionamento da descentralização das políticas sociais.

Este processo de redução da capacidade extrativa da União só teve oposição mais marcante na esfera do Executivo federal, cujos técnicos apontaram a gravidade das conseqüências destas perdas em um momento em que o país enfrentava o ponto mais agudo da crise da dívida externa e estava ameaçado pela hiperinflação.

Será sob o signo dos impasses macroeconômicos que se daria a rodada seguinte deste complexo emaranhado de relações intergovernamentais. . Como a absorção de parcelas crescentes das dívidas dos Estados vai aumentando progressivamente o peso da dívida (interna e externa) nas contas fiscais da União, buscou-se de todas as formas uma renegociação que forçasse os Estados a destinar uma parcela significativa de suas receitas ao pagamento de juros e amortizações. Embora as sucessivas negociações e renegociações tivessem poucos resultados imediatos, foi aumentando a consciência da gravidade do problema e dos perigos das soluções paliativas, que simplesmente adiassem o problema para um futuro indefinido. Em 1990, o Banco do Brasil deixou de financiar a rolagem automática dos títulos da dívida estadual, comprometendo ainda mais a situação.

A prolongada crise política que culminou com o afastamento do presidente Collor de Mello em fins de 1992, acompanhada do recrudescimento da ameaça de hiperinflação teve implicações de distinta natureza para as relações intergovernamentais. Por um lado multiplicam-se as tentativas da tecnoburocracia federal em enquadrar as finanças estaduais, mas por outro a importância dos governadores como atores políticos lhes dá condições de resistência. Através das intervenções do Senado Federal, que tem entre suas competências privativas a de dispor sobre os limites e condições do endividamento dos entes subnacionais, facilitava-se a rolagem das dívidas assumidas com a União.

Em meados de 1993, como parte dos preparativos para o lançamento do Plano Real, o então ministro da Fazenda do governo Itamar, Fernando Henrique Cardoso propõe a criação, dentro do processo em curso de revisão constitucional, do FSE-Fundo Social de Emergência, que limita o volume das transferências vinculadas a estados e municípios. A aprovação deste dispositivo foi conseguida a duras penas e explica-se pelo temor da explosão inflacionária e por seu caráter transitório (o texto referia-se apenas aos anos de 1994 e 1995). Considerada vital para dar credibilidade fiscal ao plano de estabiliza- 
ção, esta medida foi a primeira reversão na trajetória descentralizadora que se iniciara nos últimos anos do regime militar.

Com o êxito do Plano Real e a dramática queda dos índices inflacionários abre-se o caminho para a eleição de FHC e inicia-se uma nova etapa. (cf. Sola \& Kugelmas, 1995).

\section{O novo enquadramento}

Muda expressivamente a correlação de forças entre governo federal e estados, graças a um conjunto de fatores. A vitória sobre a ameaça hiperinflacionária e a eleição do novo presidente fez renascer com redobrada legitimidade a clássica tradição brasileira de presidência forte, esmaecida durante a crise que derrubou o presidente Collor. A linha mestra do novo governo era a de consolidar o processo de estabilização, o que significava o combate aos desequilíbrios fiscais e, mais a longo prazo, um ambicioso projeto de superação do velho modelo nacionaldesenvolvimentista, sintetizado na expressão "superação da era Vargas". Assim, reforma profunda do aparato estatal, e integração competitiva na ordem econômica internacional globalizada passam a ser as palavras de ordem.

Embora não houvesse um programa claramente explicitado de reformulação do quadro de relações intergovernamentais, estas seriam forçosamente afetadas. Na véspera da posse de FHC, ou seja, no último dia do ano de 1994, o Banco Central intervém nos dois principais bancos estaduais do país, o BANESPA e o BANERJ. O timing político desta medida tem implicações óbvias: evitava-se tanto os possíveis protestos dos governadores em final de mandato como uma possível reação negativa dos recém eleitos, embora tanto o paulista, Mário Covas, como o fluminense, Marcelo Alencar fossem companheiros de partido do presidente?

Durante todo o período do primeiro mandato FHC a questão do novo padrão a ser buscado nas relações entre União e estados foi marcada pelas tentativas de reenquadramento destes pelo poder central, em nome da busca de solução dos desequilíbrios fiscais. Se a partilha tributária se realizara em um momento de notável fraqueza do poder central, seria a capacidade regulatória no campo macroeconômico do governo federal, reforçada pelo êxito do Plano Real que daria os traços definidores da nova etapa. Nesta, as finanças estaduais foram duramente afetadas de distintas maneiras.

A própria queda da inflação foi um golpe de importância considerável, terminando com a corrosão das despesas, especialmente as de pessoal enquanto as receitas não se ampliavam. $O$ fim dos ganhos fáceis do floating, a perda do valor real dos depósitos não-indexados, afetou todo o sistema financeiro abalando especialmente os já enredados bancos estaduais. Também os "testamentos "dos governadores que se despediram em finais de 1994 com generosos aumentos salariais para categorias específicas e outras medidas que limitavam a ação dos seus sucessores pesaram na balança. Para completar o quadro, uma política monetária de juros elevados, como contrapartida da sobrevalorização cambial iria agravar o endividamento dos estados.
Sobre a relação Banco Central - bancos estaduais e o caso BANESPA, cf. Garman, Leite e Marques (1998). 
Abre-se então um amplo e complexo processo de reestruturação da dívida dos estados com a União, em busca de uma solução deste sempre postergado saneamento, agora explicitamente combinado com a questão dos bancos estaduais. O uso indiscriminado dos empréstimos destes para seus próprios controladores foi uma das principais fontes de poder dos governadores e um loophole, uma válvula de escape importante para os apertos orçamentários.

No caso brasileiro, as dificuldades políticas enfrentadas pelo Banco Central ao buscar enquadrar estas instituições financeiras chegaram a tais extremos que se dizia que eles teriam, na prática, o direito de emissão. A situação de ameaça hiperinflacionária e o poder politico dos governadores combinou-se para criar uma situação de erosão da autoridade do Banco Central sobre a politica monetária, fazendo dos bancos estaduais pólos rivais de poder com a capacidade de fato (obviamente não de direito) de emitir moeda. (cf. Sola, Garman \& Marques, 1998).

Graças ao êxito do Plano Real, e ao mesmo tempo para garanti-lo, o governo federal buscou atingir, de forma conjunta, o reequilíbrio da pesada carga da dívida dos Estados e o saneamento dos seus bancos. Embora a solução preferida pelo Banco Central e pelo Ministério da Fazenda fosse a privatização dos bancos estaduais, as dificuldades no encaminhamento desta proposta e especialmente a forte resistência do governo paulista quanto ao BANESPA impediram um maior avanço nesta direção durante o primeiro ano de governo.

Em dezembro de 1995, é lançado pelo governo federal o programa de apoio aos Estados, marco fundamental da reestruturação das dívidas estaduais. A partir deste momento a contrapartida dos estados que desejassem assistência financeira seria um amplo programa de reformas: compromisso com metas de ajuste fiscal, controle da folha salarial, inclusão das empresas estaduais no programa nacional de privatização, em outras palavras, um ajuste patrimonial (cf. Lopreato, 1997, p. 101). Foi estabelecido um sistema de monitoramento pela STN (Secretaria do Tesouro Nacional), semelhante ao acompanhamento das agências internacionais e não faltaram as queixas quanto ao "FMI do Malan". Este programa draconiano teve enormes dificuldades de execução; embora a maior parte dos Estados tivesse assinado os acordos, ocorreram sucessivos pedidos de adiamento e tentativas de moratória; também a tendência do Senado a acolher propostas de rolamento colaborou para retardar sua implementação. Porém, seus marcos de referência estabeleceram o balizamento, o início de um novo padrão de relações intergovernamentais.

Em consonância com esta tendência ao enquadramento, a MP 1514 de Agosto de 1996 determinou um severo conjunto de condições para a questão dos bancos estaduais ${ }^{8}$. Mimetizando a solução encontrada para o caso específico do BANESPA, são oferecidas aos governos estaduais duas opções: a primeira destas seria o financiamento do total da dívida do banco estadual em troca de sua privatização ou transformação em simples agência de fomento; a alternativa seria a manutenção do banco caso o respectivo governo pagasse imediatamente metade da dívida com recursos próprios.

No decorrer do tempo, a carga dos juros não pagos e acrescentados ao 
estoque da dívida fora crescendo de tal maneira que começa a parecer aos estados um second best aceitável o atendimento, com menos resistências, às condições apresentadas pelo poder central. O próprio peso da dívida conjunta dos Estados, calculado em torno de 100 bilhões de dólares, maior que a dívida externa de quase todos os países emergentes, demonstrava a gravidade e extensão do problema. $\mathrm{O}$ governo paulista desiste da hipótese de manutenção do BANESPA e concorda com sua federalização como preparação de uma futura privatização.

Outras manifestações de força da União neste período foram a prorrogação do FSE, agora denominado Fundo de Estabilização Fiscal e a instituição da chamada Lei Kandir, que isenta as exportações do pagamento do ICMS (Setembro de 1996). A partir do final de 1996 vai-se consolidando o novo formato, caracterizado por acordos caso a caso prevendo a troca da dívida mobiliária por uma dívida de longo prazo com a União a juros preferenciais, de 6 a 7,5\% ao ano, comprometendo-se os estados em contrapartida à utilização de parcelas entre 11 a 13\% de sua receita líquida com os pagamentos referentes a esta dívida. Os acordos incluíam também compromissos com a privatização de empresas estaduais, cortes de despesa, incluindo a promessa de obediência à Lei Camata, que limita as despesas com pessoal a 60\% da receita líquida e restrições ao endividamento futuro.

A nova situação assim foi descrita por um especialista no tema:

Os governadores, até então, haviam usado o poder político para obter favores financeiros e sustentar gastos acima do que seria possivel com base nos recursos fiscais... O programa do governo, ao negar este quadro e forçar o ajuste patrimonial dos estados, aliado ao programa de privatizações de órgãos federais, abriu uma fase de transição a um novo pacto federativo... As mudanças no ordenamento institucional, ora em gestação, interferem com as articulações financeiras presentes nas relações governamentais e restringem as possibilidades dos estados usarem a vinculação com as suas empresas e bancos para fugirem aos limites dados pela órbita fiscal (Lopreato, 1997, p. 102).

Ainda não se vislumbra, porém, qual possa ser o novo desenho institucional de relações intergovernamentais. O que se observa com nitidez é a ausência de mecanismos cooperativos mais eficazes, quer entre União e estados, quer nas relações entre estes. Tem sido utilizada a expressão "federalismo predatório "para caracterizar a situação reinante, marcada pelo perpétuo conflito em torno dos recursos a serem atribuídos a cada esfera e também pela guerra fiscal entre os estados, ansiosos por atrair novos investimentos através de mecanismos de renúncia tributária, principalmente isenções da cobrança do ICM. A ineficácia do CONFAZ-Conselho de Política Fazendária, que seria, em tese, o órgão harmonizador dos estados entre si é notória.

Uma avaliação recente dos problemas do modelo federativo brasileiro acentua este caráter predatório e a notável dificuldade em criar instru-
8 Este assunto é analisado em Lopreato (1997) e Garman, Leite e Marques (1998). 
mentos de ação que sejam eficazes na prevenção de conflitos e no estabelecimento de incentivos para um jogo cooperativo quer no sentido horizontal, entre os estados, quer no vertical, entre a União e as instâncias subnacionais. Nas palavras de seus autores:

\section{é possível dizer que se formaram dois tipos de jogos} na redemocratização. Na relação entre os estados $e$ a União, no que tange principalmente à questão financeira, predomina um jogo predatório praticado pelas unidades estaduais; na relação dos estados entre si vigora uma competição não cooperativa (Abrucio \& Ferreira Costa, 1998, p. 39-40).

Outro dado fundamental no caso brasileiro, pela singularidade da caracterização dos municípios como entes federados é o da facilidade de criação destes. De 1988 a 1997 o número de municípios no país passou de 4189 a 5507, através do desmembramento de distritos; ao serem criados, os novos municípios têm direito automaticamente a uma parcela do FPM, com o efeito perverso de pulverização da receita. Segundo uma estimativa, a quase totalidade dos menores municípios, com população até dez mil habitantes dependem do FPM na proporção de 59\% de suas receitas. (cf. Mendes 1999, p. 30).

Esta situação demonstra com clareza até que ponto a questão de reforma do Estado, objeto de tantas discussões e propostas e que foi até o campo de atuação de um ministério específico, possui uma fortíssima dimensão federativa.

A absoluta prioridade dada pelo governo à busca de um alívio às questões fiscais no trato deu o tom à busca, ainda em andamento, de um redesenho das relações intergovernamentais. O empenho pela redefinição da questão da dívida e pelo saneamento dos bancos estaduais foi acentuado no final de 1998 pela formalização de um acordo com o FMI e com o compromisso com ambiciosas metas de obtenção de um superávit primário. A fluidez da situação e a dificuldade em encontrar soluções definitivas tornou-se patente com o pedido de moratória do governo de Minas Gerais em Janeiro de 1999. Se mesmo a presença de governadores aliados nos principais estados não impedira situações conflitivas durante o primeiro mandato, como se viu no caso do BANESPA, a eleição de governadores de oposição no pleito de outubro de 1998 reforçaria os protestos contra o aperto fiscal.

\section{Políticas sociais}

Inverter a tendência centralizadora do período autoritário no que se refere às políticas sociais seria, em tese, um objetivo comum a todos os atores relevantes da cena brasileira. Quer por razões de eficácia técnica, quer por motivações ideológicas, como a identificação aliterativa entre democratização e descentralização ou mesmo pela busca pragmática pelo governo federal de uma redução de seus encargos, descentralizar é um verbo sempre conjugado nas declarações de princípio. Mais recentemente, coloca-se em dúvida a automaticidade dos benefícios da descentralização é; como descentralizar com êxito quando 
faltarem a estados ou a municípios as condições administrativas, financeira e institucionais para implementar programas? A precariedade dos mecanismos de accountability também conspira contra os entusiasmos mais ingênuos.

A avaliação desta temática requer algumas aclarações conceituais; se toda organização federativa supõe alguma forma de descentralização, a recíproca não é verdadeira, ou seja, regimes político-institucionais de tipo unitário podem conviver com fortes doses de descentralização administrativa. Além disto, é notável a variedade de situações nas federações e as imprecisões semânticas merecem atenção.

$\mathrm{Na}$ literatura especializada de relações intergovernamentais, o termo 'descentralização' está longe de ter um significado preciso. Ele tem sido utilizado indistintamente para indicar graus e modalidades diversas de redução do escopo do governo federal em decorrência: a) do deslocamento da capacidade de decidir e implementa políticas para instâncias subnacionais; b) da transferência para outras esferas de governo da implementação e administração de políticas definidas no plano federal; ou c) da passagem de atribuições da área governamental para o setor privado (Almeida, 1995, p. 90).

A experiência recente do país nos mostra um mosaico multifacetado, onde convivem experiências bem sucedidas e tentativas frustradas, vitórias e retrocessos. Como mostra um cuidadoso estudo recente, algumas tentativas de descentralização foram levadas a cabo com grande sucesso enquanto outras permaneceram nas manifestações de intenção; as diferentes trajetórias de cada política, a multiplicidade de casos e as distintas respostas dos estados dificultam as generalizações.

Porém, é possível afirmar que, com exceção da esfera da previdência, marcada por uma complexidade específica, houve um significativo redesenho do sistema anterior, fortemente marcado pela centralização autoritária. Ao fazer o balanço da década, o mencionado estudo assim resume as mudanças:

Em 1997, instâncias colegiadas estaduais, com representação paritária de estados e municípios eram responsáveis pela alocação da totalidade dos recursos da principal fonte financeira da política federal de saneamento $e$ habitação popular -o FGTS; a oferta de merenda escolar era inteiramente gerida por estados e municípios; pelo menos 33\% dos municípios brasileiros estavam habilitados a gerir os recursos federais destinados à oferta de serviços assistenciais; $58 \%$ dos municípios brasileiros estavam enquadrados em alguma das condições de gestão previstas pelo Sistema Único de Saúde -SUS, e 69\% das consultas médicas eram realizadas por prestadores federais ou estaduais (Arretche 1999, p. 140). 
Ao examinarmos as condições em que se vai desenrolando o processo de descentralização, os seguintes pontos merecem destaque e se constituem em variáveis analíticas relevantes:

- a linguagem genérica do texto constitucional, que refere-se em vários incisos à descentralização político-administrativa como "diretriz", caso do art. 198, referente ao SUS e do art. 204, referente à assistência social. São em torno de trinta os casos de competências concorrentes dos níveis de poder, o que é sinal de uma forte margem de indefinição.

- a estrutura preexistente, que pode facilitar ou dificultar um programa eficaz de descentralização.

- a estrutura de incentivos financeiros e/ou institucionais para que as instâncias subnacionais adotem uma postura ativa.

- a ênfase dada pelo governo federal à adoção efetiva de uma política descentralizadora.

No campo da educação, uma inovação de grande alcance foi a criação, pela emenda constitucional 14 (Setembro de 1996) do FUNDEF, Fundo destinado à melhoria do ensino fundamental e que prevê a transferência de recursos federais a estados e municípios para o fim específico de melhora dos salários dos professores.

Um caso interessante de êxito é o da municipalização do programa da merenda escolar, onde os recursos são repassados pela esfera federal e as vantagens para as prefeituras são grandes; em contrapartida, há desinteresse do nível municipal no caso do saneamento básico, onde os custos são grandes e não há uma política federal de incentivos.

Embora se trate de um processo em curso, algumas hipóteses podem ser sugeridas; tudo indica que as correlações políticas específicas das instâncias subnacionais são determinantes para a descentralização bem sucedida. Três casos receberam atenção internacional, os dos estados de Minas Gerais e do Ceará e a prefeitura de Porto Alegre. O programa de municipalização e de melhoria do ensino básico de Minas recebeu prêmios de organizações internacionais e o mesmo ocorreu com os esforços de combate à mortalidade infantil no estado nordestino. Também a experiência das últimas administrações da capital do Rio Grande do Sul em criar mecanismos de participação popular na elaboração orçamentária está sendo acompanhada com interesse e atenção (cf. Montero, 1998).

O que parece certoé que o florescimento das esperadas vantagens da descentralização, como maior eficiência, aumento de transparência e abertura para maior participação da sociedade civil não dependem unicamente de um real ou suposto figurino institucional mas de um contexto social e cultural mais amplo.

\section{Interrogantes e aporias}

Frente a um panorama in flux como o acima descrito, um conjunto de questões pode ser colocado. Uma conclusão inescapável é a do caráter inconcluso da institucionalização democrática no país, sendo a indefinição ainda presente do padrão de relações intergovernamentais uma das facetas mais visíveis deste 
feitio inacabado. A imprecisão dos dispositivos sobre competências concorrentes, a longa espera pela votação do conjunto de leis complementares, o caráter imediatista e ad hoc das soluções encontradas em momentos de crise, a perpétua remissão às calendas gregas da inclusão de uma reforma política na agenda, os obstáculos ao encaminhamento de uma ampla reforma tributária, tudo induz ao ceticismo. A idéia muitas vezes levantada de uma acentuada e perigosa tendência a uma paralisia decisória merece exame.

Qual o peso da dimensão federativa em uma avaliação do panorama institucional? O caráter consociativo, ou assemelhado ao consociativismo das federações é um dos componentes fundamentais do quadro brasileiro ${ }^{9}$. Como já vimos, a descentralização de recursos fiscais é extensa; um minucioso estudo comparativo sobre alguns dos principais países latino-americanos, incluindo, México, Argentina, Colômbia e Venezuela considera o Brasil como mais descentralizado do conjunto, caracterizado por "an uncommon degree of decentralization: substantial automatic transfers, weak conditionality over the use of funds, increased subnational taxing powers, and a weak delineation of responsibilities"(Willis, Garman \& Haggard, 1999, p. 40).

Retomando o quadro analítico proposto por Stepan encontraremos quatro variáveis associadas à classificação e comparação dos regimes federativos como mais ou menos majority -constraining. Estas seriam:

1- o grau de sobre-representação da câmara de representação territorial, o Senado no caso brasileiro (como também nos Estados Unidos).

2- o escopo, o grau de amplitude das atribuições desta Câmara territorial.

3- a extensão das competências constitucionalmente alocadas às entidades subnacionais, associada ao grau de dificuldade em efetuar mudanças no texto constitucional.

4- o grau de orientação nacional do sistema partidário.

Em comparação com outras federações, o Brasil surge sempre, como veremos, como o mais marcado por características de tipo descentralizador e de limitação potencial das maiorias.

No que se refere à primeira variável, a representação desigual (por vezes, mas não sempre paritária), na Câmara que representa as unidades territoriais e não o conjunto da população é característica geral dos regimes federativos. O que se discute aqui é o grau desta desigualdade. No caso brasileiro, a existência de estados esparsamente povoados como Roraima com seus 250 mil habitantes, em contraste marcante com os 31 milhões de habitantes de São Paulo ou os 17 milhões de Minas Gerais cria um caso extremo, semelhante, aliás aos EUA. No caso brasileiro ocorre outra desproporção, sem paralelo no mundo, que é o forte grau de distorção na Câmara de Deputados, que, como em outros regimes bicamerais deveria representar o conjunto da população do país. A existência de um limite inferior de oito deputados por estado e um limite superior de 70, dá origem a um quadro que já foi descrito como de "egregious malapportionment” (Mainwaring, 1999, p. 267). A criação em 1988 de quatro novos estados (os antigos territórios federais do Acre, Roraima e Amapá e o
${ }^{9}$ As possibilidades e dificuldades do uso deste conceito são discutidas em Lamounier (1995), Souza (1997), Couto (1997) e Azevedo \& Melo (1997). 
estado de Tocantins, desmembrado de Goiás), além da atribuição de representação ao Distrito Federal significou, de uma só vez, a presença de mais quinze senadores e quarenta deputados no Congresso Nacional aumentando a já fortíssima sobre-representação das regiões menos desenvolvidas. Assim, as regiões Nordeste, Norte e Centro-Oeste, especialmente estas duas últimas são beneficiadas por uma representação parlamentar superior a seu peso populacional. Segundo uma estimativa de Stepan, seria possível, ao menos em tese, a formação de uma coalizão majoritária no Senado formada por senadores que representassem treze por cento do conjunto da população (cf. Stepan 1997, p. 34).

No que se refere à segunda variável, o Senado brasileiro tem nada menos que doze áreas de competência exclusiva, incluindo, como já foi visto, a de aprovar os limites de endividamento estadual, tornando-o um dos principais atores na questão mais estratégica para a redefinição das relações intergovernamentais. No Brasil, como nos EUA e em contraste com outras federações a amplitude das atribuições da Câmara Alta é enorme. Isto torna especialmente significativos os efeitos potenciais de uma coalizão regional.

Com relação à terceira variável, já vimos a extensão das atribuições (ao menos nominais) das entidades subnacionais no caso brasileiro; também a competência residual cabe aos estados, na tradição constitucional do país. Se levarmos em conta o efeito das variáveis já apontadas anteriormente sobre o ritual do processo de reforma constitucional-aprovação em dois turnos por uma maioria qualificada de três quintos em cada uma das duas casas do Congresso -mais uma vez colocaremos o Brasil no ponto extremo do gradient proposto por Stepan, ou seja, como um dos casos onde é mais nítida a presença de mecanismos majority constraining.

Se tomarmos a quarta variável, a notória ausência no caso brasileiro de um sistema partidário forte e disciplinado, orientado para temas de escopo nacional é mais uma fonte de fragmentação e descentralização de poder.

Diante deste quadro é difícil escapar da conclusão de que temos no Brasil um caso extremo de fragmentação de poder, levantando a ameaça da ingovernabilidade. Há, porém, um outro lado da moeda, que é o da extensão dos recursos de poder do Executivo federal e especialmente o poder da Presidência da República: uma avaliação mais cuidadosa terá que levar em conta que, apesar de tudo, foi possível implementar um programa de estabilização, encaminhar importantes reformas constitucionais e estabelecer limitações fiscais aos estados.

As possíveis coalizões congressuais de completo bloqueio às propostas do Executivo são mais que nada uma ameaça potencial e influem sobre a composição da agenda, comoé especialmente visível nas dificuldades em encaminhar a reforma tributária e a reforma política. Esta última não consegue se consolidar na agenda do país e não se vislumbra uma solução para o clássico problema da reforma que deve forçosamente ser votada pelos atuais beneficiários de um sistema enviesado de representação. Também a reforma tributária é sabidamente um exemplo deste "poder de veto não formal" (Azevedo \& Melo, 1997, p. 91), que acaba por limitar e enquadrar as próprias propostas das elites técnicas.

Por outro lado, um conjunto de fatores dá margem de manobra às pro- 
postas do Executivo. O caráter plebiscitário das eleições presidenciais conferindo uma legitimidade especial de grande peso na cultura política brasileiraé um deles, bem como a notável soma de poderes da tecnoburocracia federal. Aliás, é exatamente nos estados pequenos e pobres que o Executivo, em muitos momentos, constrói uma base de apoio de tipo clientelístico. (cf. Mainwaring, 1999, p. 271).

Tudo indica, porém, que estamos chegando ao limite destas "soluções "de tipo imediatista, e pouco congruente com uma consolidação de práticas republicanas. O regime federativo no país é um dos elementos constituintes de um imbroglio político-institucional caracterizado por uma multiplicidade de veto points. Deve ser lembrado que a preocupação com as reformas e o problema da governabilidade não é apenas uma queixa do Executivo federal e independe do conteúdo específico das políticas por este defendidas. Não é difícil imaginar a extensão das dificuldades que um presidente eleito pela atual oposição teria em realizar seu programa.

É constante, talvez diária a presença de apelos por um novo pacto federativo na mídia, nos discursos parlamentares, nos seminários acadêmicos. Não parece possível nem provável que tal pacto possa ser urdido a partir da preocupação quase exclusiva do governo com a questão fiscal, ou da defesa ingênua da descentralização como benfazeja por definição.

É necessário enfrentar de forma criativa os desafios da etapa atual, como faz Manuel Castells ao propor o Estado-Rede, associação de blocos regionais, estados nacionais, diversos tipos de instâncias subnacionais, associações da sociedade civil, organizações não governamentais, interligadas por redes de parceria e cooperação (cf. Castells, 1998).

Mais do que um pacto definitivo, talvez inatingível, deve-se pensar em um processo contínuo de redefinição e aperfeiçoamento da dimensão federativa que está presente na própria idéia de reforma do Estado e do sistema político em seu conjunto. Mais do que nada é a questão da recuperação plena do caráter republicano das instituições que deve nortear estes esforços.

Recebido para publicação em novembro/1999

KugELMAS, Eduardo \& SoLA, Lourdes. Recentralization/Decentralization: dynamics of the federative regime in Brazil 90's. Tempo Social; Rev. Sociol. USP, S. Paulo, 11(2): 63-81, Oct. 1999 (edited Feb. 2000).

ABSTRACT: This article discusses the evolution of the federative practice and institutions in Brazil in the past few years, emphasizing the simultaneity of the decentralization processes. The decentralizing trajectory which culminates in the 1988 Constitution, the fiscal crises of the Brazilian State and the effects of Plano Real are discussed based in a set of comparative references, trying to incorporate very recent works by Alfred Stepan.

UNITERMS: federalism, public policies. 


\section{REFERÊNCIASBIBLIOGRÁFICAS}

Abrucio, Fernando. (1998) Os barões da federação. São Paulo, Hucitec/Edusp. \& Ferreira Costa, Valeriano. (1998) Reforma do Estado e o contexto federativo brasileiro. Série Pesquisas nํ⒓ São Paulo, Fundação Konrad Adenauer.

Afonso, José Roberto Rodrigues \& Lobo, Theresa. (1996) Descentralização fiscal e participação em experiências democraticas retardatárias. Planejamento e Políticas Públicas, Brasília, 14: 5-22, dezembro.

Aguirre, Basilia \& Moraes, Marcos R. (1997) A questão federativa no Brasil: um estado das artes da teoria. Revista de Economia Política, São Paulo, 17(1): 121-135 (65), janeiro-março.

AlmEIDA, Maria Herminia Tavares de. (1995) Federalismo e políticas sociais. Revista Brasileira de Ciências Sociais, São Paulo, 10 (28): 88-108, junho.

Arretche, Marta T. S. (1999) Políticas sociais no Brasil: descentralização em um Estado federativo. Revista Brasileira de Ciências Sociais, São Paulo, 14(40): 111-141, junho.

Azevedo, Sérgio \& Melo, Marcus A. (1997) A política da reforma tributária: federalismo e mudança constitucional. Revista Brasileira de Ciências Sociais, 12(35): 75-99, outubro.

Campello de Souza, Maria do Carmo. (1976) Estado e partidos políticos no Brasil-1930/1964. São Paulo, Alfa-Ômega .

Carmagnani, Marcello (org.). (1993) Federalismos latinoamericanos México, Brasil, Argentina. Mexico, Fondo de Cultura.

Castells, Manuel. (1998) Rumo ao estado rede? São Paulo, mimeo.

Couto, Claudio G.(1997) A agenda constituinte e a difícil governabilidade. Lua Nova, São Paulo, 39: 33-52.

Dillinger, William \& WebB, Steven. (1999) Fiscal management in Federal democracies:Argentina and Brazil. (Policy research working paper 2121). Washington, World Bank.

ElazAR, Daniel. (1987) Exploring federalism. Tuscaloosa, University of Alabama Press.

FIORI, José Luis. (1995) O federalismo diante do desafio da globalização. In: Affonso, Rui \& Barros Silva, Pedro Luís (orgs.). A federação em perspectiva. São Paulo, Fundap, p. 19-38.

GAGnON, Alain. (1993) The political uses of federalism.In: $\&$ BuRgEss, Michael. (orgs.). Comparative federalism andfederation. London, Harvester, p. 9-23.

Garman, Christopher, Leite, Cristiane \& Marques, Moisés. (1998) Impactos da relação Banco Central versus bancos estaduais; análise à luz do caso Banespa. (mimeo) Caxambu, ANPOCS. 
LAmounier, Bolivar. (1996) A democracia brasileira no limiar do século 21. São Paulo, Fundação Konrad Adenauer. (Série Pesquisas, no 5)

LijPhart, Arend. (1984) Democracies. New Haven, Yale University Press.

Lopreato, Francisco L.C. (1997) Um novo caminho do federalismo no Brasil? Economia e Sociedade, Campinas, 9: 11-25, dezembro.

MaInwaring, Scott. (1999) Rethinking party systems in the third wave of redemocratization: the case of Brazil. Stanford, Stanford UniversityPress.

Mendes, Marcos J. (1999) Incentivos eleitorais e desequilíbrio fiscal em Estados e municípios. (mimeo). São Paulo, Instituto Fernand Braudel de economia mundial.

Montero, Alfred. (1998) Devolving democracy? Political decentralization and the new Brazilian federalism. Internet-http://public.carleton.edu/ $\sim$ Amontero/kingpow.htm

RIKER, William. (1964) Federalism: origin, operation, significance. Boston, Little \& Brown.

SALLUM JR., Brasilio. (1996) Federação, autoritarismo e democratização. Tempo Social, São Paulo, 8(2): 27-52, outubro.

Sola, Lourdes, Garman, Christopher \& Marques, Moisés. (1998) Central banking, democratic governance and political authority: the case of Brazil in a regional perspective. Revista de Economia Política, São Paulo, 18(2): 106-131, abril-junho.

Sola, Lourdes \& Kugelmas, Eduardo. (1996) Statecraft, instabilidade econômica e incerteza política: o Brasil em perspectiva comparada. In: DinIz, Eli (org.). O desafio da democracia na América Latina. Rio de Janeiro, Iuperj, p. 398-414.

SouzA, Celina. (1997) Constitutional engineering in Brazil. London, Macmillan Press.

STEPAN, Alfred (1997) Towards a new comparative analysis of democracy and federalism. (mimeo). Oxford.

StePAn, Alfred \& Linz, Juan (1996) Problems of democratic transition and consolidation: Southern Europe, South America and PostCommunist Europe. Baltimore, Johns Hopkins.

ToRres, João Camilo de Oliveira (1961) A formação do federalismo no Brasil. São Paulo, Companhia Editora Nacional.

VERSANO, Ricardo et alii. (1998) Uma análise da carga tributária no Brasil. Rio de Janeiro, IPEA.(Texto para discussão, nํ583).

WhEARE, Kenneth. (1970) Federal government. Oxford, Oxford University Press.

Willis, Eliza, Garmas, Christopher \& HagGard, Stephan (1999) The politics of decentralization in Latin America. Latin American Research Review, Albuquerque, 34(1): 7-56. 